\title{
COMMUNICATIVE FUNCTIONS OF HASHTAGS
}

\author{
Aleksandra Laucuka \\ The University of Latvia, Riga, Latvia, liauchuka@gmail.com
}

\begin{abstract}
Despite the initial function of hashtags as tools for sorting and aggregating information according to topics, the social media currently witness a diversity of uses diverging from the initial purpose. The aim of this article is to investigate the communicative functions of hashtags through a combined approach of literature review, field study and case study. Different uses of hashtags were subjected to semantic analysis in order to disclose generalizable trends. As a result, ten communicative functions were identified: topic-marking, aggregation, socializing, excuse, irony, providing metadata, expressing attitudes, initiating movements, propaganda and brand marketing. These findings would help to better understand modern online discourse and to prove that hashtags are to be considered as a meaningful part of the message. A limitation of this study is its restricted volume.
\end{abstract}

Keywords: hashtags; social networks; pragmatics; communicative functions

\section{Introduction}

In the last decades, the use of social media platforms has been constantly growing, and so has been the need to categorize huge amounts of information and to develop tools for finding what users are searching for. Hashtags became an everyday reality of the frequenters of social networks: Twitter, Facebook and Instagram, and even messengers like WhatsApp now offer the feature. But a brief glance into the web environment reveals that hashtags have become much more than just topic markers - people use hashtags for anything, from proselytizing to informing the readers, what smartphone model the author possesses.

The trigger of the current research was an Instagram phenomenon, whereby pictures were frequently matched with seemingly irrelevant tag words. If hashtags were only identifying the topic(s) of the photo according to the definition, a selfie of a woman on a seashore would presumably feature \#seashore \#ocean \#woman \#nature \#landscape \#walk, maybe \#sunset or \#sunrise, possibly some toponym like \#jurmala or \#miami, and similar words. Instead, it is not infrequent to see such pictures marked with all sorts of words and phrases ranging from philosophical (\#love, \#daydreaming) and technical (\#iphonephotography, \#vscocam) to anything up to \#whatamidoinghere and personal branding (\#luxurylife, \#wildandfree). Apparently, users try to communicate additional information through the crosshatch - hence, the interest that provides the impetus for the current article and defines the research question: what are the communicative functions of hashtags?

To answer the research question, in this article, we conduct a literature review with the purpose of aggregating the knowledge already existing in the domain. Some features that could not be derived from the literature review will be taken from a case study, to supplement the theoretical findings. All mentions of different functions are supported by numerous examples sampled directly from the relevant web environments. The examples are subjected to qualitative semantic analysis, content analysis and discourse analysis.

The results section features findings that include: topic-marking, aggregation, socializing, excuse, irony, providing metadata, expressing attitudes, initiating movements, propaganda and brand marketing. 


\section{Literature Review}

The use of hashtags in general has been a popular research topic recently, as academic interest is driven by the ever-increasing use of the tool in modern human communication. The cross-hatch communicative functions in particular were studied from different perspectives by Peter Wikstrom and Michele Zappavigna, among others.

Peter Wikstrom (2014) approached the hashtags on Twitter from the point of view of linguistic pragmatics after having noticed that a traditional speech acts framework is applicable in social media studies. He demonstrated that hashtags are not solely categorizing labels, but they are also used for structuring, playing and providing meta-comments (Wikstrom 2014).

Zappavigna, approaching the same topic from the point of view of social semiotics, conducted discourse analysis in a 100-million-word Twitter corpus, and investigated three functions: 'marking experiential topics, enacting interpersonal relationships, and organizing text' (Zappavigna 2015:1).

Many authors (Boellstorff [2012], Burns [2017], Lupton [2015], Meikle [2016], Rasmussen Neal [2012] to name just a few) have noticed that hashtags are being adopted for different purposes, from irony to marketing, and nobody argues that the cross-hatch sign is still used as it was initially intended to. A more detailed analysis of these and other scholars' findings is imbedded into the current article, accompanied by examples and evidence collected by the author from social media platforms like Twitter, Instagram and Facebook.

'In sum, the findings reveal that users of Twitter have, to a significant extent, appropriated the hashtag organizing and categorizing device for other purposes, sometimes completely removed from the expected functionality' (Wikstrom 2014:24).

\section{Methodology}

To answer the question: 'what are the communicative functions of hashtags?', we will conduct a literature review, supported by verification through a field study (or rather web study) to effectuate the current trend analysis. The research question pertaining to the domain of pragmatics and cultural studies mainly requires qualitative semantic analysis, content analysis and discourse analysis. If not supported by evidence in the original texts, the observations of the cited authors will be supplemented by examples from the web found by the author of the current article. A case study with content analysis will be presented in order to demonstrate some particular uses of hashtags that are not retrievable from the quantitative analysis. Examples are retrieved from one of the three social platforms under question: Twitter, Instagram and Facebook, and obtained from discoverable posts marked for public use by hashtags. The search is conducted via the relevant tools provided by the platforms themselves.

Although all the tweets and posts that are used for analytic and demonstrational purposes here are public, it is considered a good practice to protect informants from unnecessary exposure. Whereas people are sometimes highly anonymous on Twitter, hiding their identities under nicknames, some other users reveal their real names and faces online, which is frequently the case in Instagram. Tom Boellstorff and colleagues recommend to 'Avoid the inappropriate revelation of the identities of informants - or any sort of confidential details or otherwise - that might lead to their identification' (Boellstorff et al. 2012, cited in: Lindgren 2017: 241). The so-called 'private' hashtags are highly valuable as such for our research purposes, but due to social media research ethics and respect for users' privacy, it was deemed reasonable to conceal them under tokens to dissociate from real people. They will be further accounted for in the codified form that reveals the essence of the message but hides the identity.

By definition, a hashtag is 'a word or phrase preceded by a hash sign (\#), used on social media websites and applications, especially Twitter, to identify messages on a specific topic' (ODE). A good example of this are hashtags like \#vegan, \#FIFAcup2014 and \#LinkinPark that provide a plethora of shared experiences and opinions on the relevant topics. A post published in one's own timeline is 
effectively invisible to the broader public beyond the user's friends and maybe friends' friends unless it's tagged.

In terms of grammar and syntax, the keywords are not restricted to their role as outstanding labels, but can also be smoothly integrated into the discourse, forming grammatical sentences:

\#SocialCare who are \#useless I'm \#disgusted! \#threegirls

Whilst the \#police made mistakes, they have to listen to supposed 'professionals' (both examples from Twitter)

The above examples look like a smooth text, and the keywords are used to mark topics, to present the authors' opinions on the matters and to share them with other users.

When an internaut clicks on a hashtag, he or she is instantly offered an assortment of tweets, posts or photos (depending on the platform) marked with the keyword in question. Besides topic-marking that goes by definition, 'the hashtag also serves the function of linking content into a larger conversation about a specific topic on Twitter' (van den Berg 2014:5). Sometimes producers of TV shows (\#BezTabu) or organizers of conferences (\#LTC_conf) provide their audience with hashtags to share their opinions in real time and comment what's happening on the stage, to ask questions to the speakers and to communicate with other viewers/participants. Meikle summarizes this purpose as: 'to aggregate voices, information and commentary around a common theme' (Meikle 2016:76), so we can use the word aggregation. However, it is effectuated imperfectly, because people often use different hashtags to mark the same topics (e.g., \#WorldCup2014 and \#Brazil2014), as well as keywords in different languages (Sloan, Quan-Haase 2017:112). For example, \#prayforparis was used to express condolences to all those who suffered in the terrorist attacks in the capital of France, and generally the mould \#prayforCITY is used as a standard marker for the locations of tragedies (\#PrayForManchester, \#PrayForLondon, \#PrayForNice, \#PrayForBerlin, etc.). On the other hand, highly touching events produce an array of newly-coined hashtags (\#PrayingForParis, \#ParisAttentats, \#jenaipaspeur, \#jesuismuslim and many others) that becomes a vocabulary in its own right. Every user can then pick an appropriate tag to highlight what is the most important for them, to attenuate their stance and still be a part of the global conversation.

If everybody agreed that topic-marking and aggregation were the only functions of hashtags, it would be easy to find the targeted information, because people would then only indicate the appropriate keywords. Unfortunately, if you try to find photos of \#Malta or \#GrandCanyon on Instagram, about half of the results are selfies with a fraction or no landscape in the frame. This leads one to think that the authors of the pictures have a communicative function in mind rather than them trying to offer a nice photograph of the natural wonder to whoever seeks it. People do not just go to places, they socialize by sharing their experiences. This opinion finds support with other authors: "while popularly thought of as topic-markers, hashtags are able to construe a range of complex meanings in social media texts' (Zappavigna 2015). In the field, internauts describe their feelings by the Grand Canyon as \#spectacular, \#unforgettable and \#amazing, whereas New York and San Francisco disappoint them by \#toomuchtraffic. Some users are being as explicit as \#ontopoftheworld, \#theworldmustknowwhatieat and \#hegavemeflowers. Interestingly, the last two would also appear to be used as an ironical and selfmocking excuse for displaying one's flowers and food. Speaking about irony, it is made pretty obvious when a hashtag contradicts the message, as in:

So I heard that trump was ending child support in 2018. \#VOTEFORTRUMP (example from Twitter)

Let us proceed with a brief case study of an Instagram post that epitomizes the outlined tendency. It features a woman in some natural setting, and the picture is accompanied by a string of hashtags:

'Evening and morning \#SOMESPORTcamp* \#ADVENTUROUS_NATIONAL* \#daydreaming \#iphonephotography \#nature \#portugal \#sagres \#sunset \#work \#love \#EAT_PRAY_LOVE*'.

The asterisks mark three hashtags, that could not be presented here in their original form due to social media research ethics and respect for user privacy, as it will be further demonstrated that these are rather private tags. Referring to the privacy protection recommendation mentioned in the Methods 
section (Boellstorff et al. 2012, cited in: Lindgren 2017: 241), we will henceforth conceal the 'private' hashtags under tokens. As these tag words are valuable for demonstration and analytical purposes, therefore they will be further accounted for in the codified form that reveals the essence of their message. \#SOMESPORTcamp identifies a sports camp devoted to certain disciplines, \#ADVENTUROUS_NATIONAL defines the user as her country's national of an adventurous spirit, \#EAT_PRAY_LOVE denotes a life philosophy, formulated as a string of verb infinitives and structured in the same way as the title of a famous book 'Eat, pray, love'.

In the Instagram post described above, almost no hashtag could be linked with something depicted on the photo (except, maybe, \#portugal, because a Portuguese seascape is indeed there). Instead, hashmarked words are used to provide additional information, both of a personal character and the socalled metadata. 'Metadata is information appended to some primary form of content to assist in retrieving and understanding that content when it is stored or published (e.g., information about when and where a social media post was produced)' (Zappavigna 2015). To illustrate the point, we could mention Instagram food recipes marked with \#glutenfree and \#vegan (information on ingredients), items tagged \#luxury, \#almostforfree, \#costsafortune and some brand like \#prada (to indicate price range), \#earlymorningphoto (the time when the picture was taken) and \#iphonexcamera (the tool).

Thus, in the post \#portugal indicates the country where the photo is taken; \#sagres indicates a more precise location within the country; \#SOMESPORTcamp denotes what the woman was doing during her stay there; \#daydreaming suggests what the woman was presumably doing at the exact moment when the photo was taken (although there are reasons to think she was posing for the photographer); \#ADVENTUROUS NATIONAL must be the personality the woman associates herself with; \#iphonephotography should be the method; \#nature is the general setting; \#sunset is not present in the photo but maybe it is happening outside of the frame, on the line of sight of the woman; \#work must be related to the sports camp mentioned before (and the followers of the lady know it is); \#love must indicate either the mood of the general philosophy of the woman and \#EAT_PRAY_LOVE clearly represents the lifestyle and philosophy the lady preaches. So, we can say that five of these hashtags provide metadata and allow to find specific information (\#SOMESPORTcamp \#iphonephotography \#portugal \#sagres \#nature), the other six are employed to create mood and showcase a certain lifestyle (\#ADVENTUROUS_NATIONAL \#daydreaming \#sunset \#work \#love \#EAT_PRAY_LOVE). Here are the data on the frequency of the hashtags in question.

Table 1. The frequency of selected hashtags on Instagram (Source: author's compilation as of 4 June 2017)

\begin{tabular}{|l|l|}
\hline \#love & $1,078,950,520$ \\
\hline \#nature & $232,102,907$ \\
\hline \#sunset & $133,399,896$ \\
\hline \#work & $87,317,433$ \\
\hline \#portugal & $14,994,877$ \\
\hline \#iphonephotography & $6,096,467$ \\
\hline \#daydreaming & 860,993 \\
\hline \#sagres & 162,553 \\
\hline \#ADVENTUROUS_NATIONAL & 99 \\
\hline \#SOMESPORTcamp & 3 \\
\hline \#EAT_PRAY_LOVE & 1 \\
\hline
\end{tabular}

As can be seen from Table 1, general words are used as hashtags much more often than specific ones. Taking the point further, three of the lifestyle hashtags prove to be very specific: \#ADVENTUROUS_NATIONAL is only employed by this particular user, totalling 99 posts; 
\#SOMESPORTcamp has 3 photos, two of which are from the same user; \#EAT_PRAY_LOVE is unique. Obviously, these hashtags cannot be used to join a conversation on the relevant topic, because there is none. Also, they are scarcely browsed for because otherwise they would be in a greater demand. These are hardly metadata, because they don't describe anything pertaining to the picture. Instead, these words perform a communicative function, allowing the user to describe herself and project the vision $-\mathrm{a}$ form of personal branding.

In addition to referring to certain topics, 'microbloggers [...] construe attitudes toward those topics and enact relationships with the ambient audience' (Zappavigna, 2015). A sociologist Deborah Lupton shares her first-hand online experience and says that the keywords 'can sometimes be sarcastic or critical as part of efforts to entertain others or denote one's emotional responses to content. One common example is the use of hashtag symbol (\#) on Twitter, which not only serves to classify content [...], but is also often used as a way of expressing opinion or evaluation (\#excited, \#disgusted).' (Lupton 2015: 10-11). Different attitudes and emotions are frequently expressed by verbs or adjectives that describe people's moods, attitudes, opinions or emotions:

Tattoo no.5 booked. :) \#excited

When you find out things you really wish you didn't \#upset \#seriously (Both examples from HERMES2013 Twitter corpus, mentioned in: Zappavigna, 2015)

Putting hashtags like these allows authors to clearly denote their attitude and avoid ambiguity.

Mohammad and Kiritchenko conducted an experiment to see if emotion-related hashtags in Twitter correlate well with the moods of the posts. They collected a corpus of tagged posts from several thousand people and asked trained judges to provide their annotations on what they perceive from the posts. It turned out that hashtags describe emotions very well, and that this labelling is used consistently by thousands of users (Mohammad, Kiritchenko 2013:22).

Speaking of hashtags as tools to aggregate different opinions, some authors suggest broader persuasive opportunities here: 'the hashtag's function of adding the opinion of an individual to the confluence of opinions contributed by others, confirms the possibility of not only grouping information thematically, but also of opening up movements in this regard, with exponential dynamics' (van den Berg 2014). Demonstrating these options are, among others, the \#metoo wave that spread in October 2017, bringing to light issues of sexual harassment and causing serious repercussions including the Me Too Bill in the US Congress (NPR.org, 2017). \#icebucketchallenge went viral in 2014, allowing the ALS (Amyotrophic lateral sclerosis) Association to raise $\$ 115$ million in donations during an 8-week period, in addition to $\$ 77$ million dedicated to research, 3 new genes discovered, 15,000 patients helped per year, 150+ active research projects funded and other important social developments (ALSA). 'Hashtag activism, as is it also called, embraces Twitter as a tool for instant propagation of social causes, and Twitter is a powerful weapon in the hands of grassroots groups and NGOs like Greenpeace to harness consumer awareness or organize boycotts' (Van Dijck 2013: 87). Clearly, the tool is also used by political activists (\#VoteForTrump, \#gāztNilu). If exploited wisely, hashtags due to their democratizing nature may help one to obtain unbiased opinions, comprehensive and objective information; for example, Kaczmirek et al. describe how they used thematic hashtags on Twitter in order for their data to not be 'restricted to communication around specific Bundestag candidates or journalists' (Kazcmirek et al. 2014:11, cited in: Sloan, Quan-Haase 2017:116-117).

The persuasive and promulgating functions of hashtags are of interest not only to the politicians but also to the representatives of the church. Van den Berg, for example, wrote a whole article about the benefits of hashtags for 'practical theology' and the opportunities presented by social media. He also mentions that 'The popular theologian, Leonard Sweet has for example already encapsulated some of the aspects of this challenge in his article, "Twitter theology: 5 Ways Twitter has changed my life and helped me be a better disciple of Jesus", indicating that "Twitter makes me a better Jesus disciple, partly because Twitter is my laboratory for future ministry" (Sweet 2009, cited in van den Berg 2014:5). Needless to say, \#jesuslovesyou counts millions in social media. Be their applications religious or philosophical, hashtags like \#jesuismuslim and \#notafraid are frequently used in posts 
about terrorist attacks. This demonstrates that online users employ tags to defend and promulgate their faith or philosophy.

Writing on social media for academics, Rasmussen Neal states that 'hashtags are used to give your followers an easy way of categorizing your tweets' (Rasmussen Neal 2012:108) with an added benefit of collecting related materials. She also mentions a good tweetiquette: 'to do a Twitter search before inventing your own hashtags, in case someone else has already begun categorizing tweets with the same hashtags' (ibid). This approach is not only useful for academics; for example, the lady from our case study used the \#ADVENTUROUS_NATIONAL 99 times at the time, thus creating a separate category for all her adventurous posts.

The last three examples - politics, church and academics - may be viewed as promotional and reputational, which brings us to the hashtag use that could be described as marketing or branding. It is not infrequent for brand managers to use their corporate hashtag, but also to create additional ones for certain events (\#lattelecomrigamarathon), products (\#nikeprobra) or collections (\#maxmaragram); in addition, they 'encourage the use of certain hashtags for users to share a photo to enter a contest or participate in another type or promotion' (Burns 2017: 35) - \#vefgrozs vai \#EsGribuSavusPalladium. People might also promote themselves as personal brands through hashtags with their names, surnames or nicknames, by marking some domain (\#NAMEfit, \#NAMEmodel) and also by continuously using a word or phrase that no one else uses.

\section{Results}

The results of this investigation suggest that hashtags are not only topic-markers and aggregators, which was their initial purpose, but that they apparently have numerous other applications. This study has identified the following functions:

- marking the topic(s) of a post (\#vegan, \#elections)

- aggregation of information on a certain topic (\#prayforparis, \#Brazil2014)

- socializing and sharing experience (\#amazing, \#toomuchtraffic, \#ontopoftheworld)

- excuse (\#hegavemeflowers and \#theworldmustknowwhatieat)

- irony (when a hashtag contradicts the message)

- providing additional information and/or metadata: geographic location, price, brand, ingredients and so on (\#glutenfree, \#costsafortune, \#iphonexcamera)

- marketing and (personal) branding (\#ADVENTUROUS_NATIONAL, \#maxmaragram)

- expressing attitudes like opinions, emotions and evaluations (\#disappointed, \#excited, \#seriously)

- initiating movements (\#icebucketclhallenge; \#metoo)

- promulgation of certain views and philosophies (\#EAT_PRAY_LOVE, \#jesuslovesyou, \#voteforX, \#notafraid)

This shows that internauts have not merely accepted the classificatory tool that was offered to them, but also succeeded in expanding its range of uses. Hashtags have become a legitimate way to write any metacomments that users do not want to state directly. Many of these mentions are face-protecting and allow users to brag in a less arrogant manner (like \#hegavemeflowers, \#iphonephoto or \#luxurylife). Isolation, different colouring and the special sign make these additional words look like system markup, rather than something that user has written herself, about herself.

Hashtags' power to make any post visible to an immense audience is also exploited to the fullest: for political and religious propaganda, for brand and personal marketing, even for initiating huge flashmobs that change lives.

\section{Conclusions}

The purpose of the current study was to determine the communicative functions of hashtags. Through a combined approach of literature review, field study and case study, ten communicative functions 
were identified: topic-marking, aggregation, socializing, excuse, irony, providing metadata, expressing attitudes, initiating movements, propaganda and brand marketing.

The principal theoretical implication of this study is that the pragmatic applications of hashtags have expanded to a broader range than it was initially conceived. We have identified ten different communicative functions, but the list cannot be presented as definitive since neither the literature review nor the field study were by no means exhaustive. This is due to the fact that the scope of this study was limited in terms of volume. The findings would help to better understand the modern online discourse and to prove that hashtags are to be considered as a meaningful part of the message. Further studies would be worthwhile to fully understand the diversity of implications of hashtags in the social media.

\section{References}

The ALS Association (n.d.) Progress Since the Ice Bucket Challenge. [Accessed 4.06.2017] Available from Internet: http://www.alsa.org/fight-als/edau/ibc-progress-infographic.html.

Boellstorff. T., Nardi, B., Pearce, C. \& Taylor, T. L. (2012) Ethnography and Virtual Worlds. Princeton, NJ: Princeton University Press.

Burns, K. S. (2017) Social Media. ABC-CLIO: Santa Barbara/Denver, USA.

Kaczmirek, L., Mayr, P., Vatrapu, R. et al. (2014) Social Media Monitoring of the Campaigns for the 2013 German Bundestag Elections on Facebook and Twitter. GESIS working papers. [Accessed 21.03.2018] Available from Internet: https://www.gesis.org/fileadmin/upload/forschung/ publikationen/gesis_reihen/gesis_arbeitsberichte/WorkingPapers_2014-31.pdf

Lindgren, S. (2017) Digital media \& society. London: SAGE.

Lupton, D. (2015) Digital Sociology. London and New York: Routledge.

Meikle, G. (2016) Social Media. Routledge: New York and London.

Mohammad, S. \& Kiritchenko, S. (2013) Using Hashtags to Capture Fine Emotion Categories from Tweets. Ottawa: National Research Council.

NPR.org (15.10.2017) 'Me Too' Legislation Aims To Combat Sexual Harassment In Congress. [Accessed 6.04.2018] Available from Internet: https://www.npr.org/2017/11/15/564405871/me-too-legislation-aims-tocombat-sexual-harassment-in-congress

ODE, Oxford Living Dictionaries, https://en.oxforddictionaries.com/

Rasmussen Neal, D. (2012) Social Media for Academics. Oxford: CP Chandos Publishing.

Sloan, L. \& Quan-Haase, A. (2017) The SAGE Handbook of Social Media Research Methods. London: SAGE.

Sweet, L. (2009) Twitter theology: 5 Ways Twitter has changed my life and helped me be a better disciple of Jesus. [Accessed 26.05.2017] Available from Internet: http://www.eeuwigheid.nl/twitter-helpt-jezus-navolgen

Van den Berg, J.A. (2014) The story of the hashtag (\#): A practical theological tracing of the hashtag (\#) symbol on Twitter. HTS Theological Studies 70(1), art. 2706.

Van Dijck, J. (2013) The Culture of Connectivity. A Critical History of Social Media. Oxford: Oxford University Press.

Wikstrom, P. (2014) \#srynotfunny: Communicative Functions of Hashtags on Twitter. SKY Journal of Linguistics, Vol. 27, p. 127-152. [Accessed 10.04.2018] Available from Internet: http://www.linguistics.fi/julkaisut/SKY2014/Wikstrom.pdf

Zappavigna, M. (2015) Searchable talk: the linguistic functions of hashtags. Social Semiotics, 2015, Vol. 25, No. 3, 274-291. Sydney: University of New South Wales 